JAOS

mansera

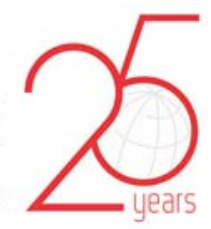

\title{
Human plasma fibronectin promotes proliferation and differentiation of odontoblast
}

\section{Abstract}

Jia TANG ${ }^{1}$

Takashi SAITO ${ }^{1}$
Submitted: September 2, 2016 Modification: November 6, 2016

Accepted: December 18, 2016
Objective: To assess the effect of fibronectin ( $F n)$ and porcine type I collagen (PCOL) on odontoblast-like cells in vitro. Material and Methods: Rat odontoblast-like cells (MDPC-23 cells) were inoculated and cultured on Fn-coated or type I collagen-coated substrates. Proliferation assay, alkaline phosphatase activity (ALP activity), mRNA expression of hard tissue-forming markers, and Alizarin red staining were investigated over a period of 10 days. Results: Cells maintained a high proliferation activity on Fn and PCOL even at a low seeding concentration $\left(0.5 \times 10^{4} / \mathrm{mL}\right)$ as demonstrated by CCK- 8 assay. The proliferation activity of cells on $\mathrm{Fn}$ increases in a concentrationdependent manner while it reached a plateau after $10 \mu \mathrm{g} / \mathrm{mL}$. Cells adopted long, thin and spindle shape on $\mathrm{Fn}(10-50)$ and PCOL. Parallel actin filaments were observed in MDPC-23 cells cultured on Fn and PCOL. ALP activity was markedly up-regulated on Fn and PCOL-coated surfaces. Importantly, gene

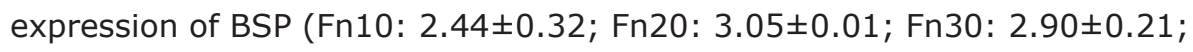
Fn40: 2.74 \pm 0.30 ; Fn50: 2.64 \pm 0.12 ; PCOL: $2.20 \pm 0.03)$ and OCN (Fn10:

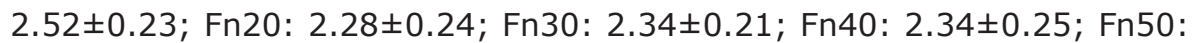
2.20 0.22 ; PCOL: $1.56 \pm 0.16$ ) was significantly enhanced on Fn and PCOL substrates as compared with control; moreover, expression of integrin beta 1 (ITGB1), an ubiquitous cell surface receptor was augmented in $\mathrm{Fn}(10-50)$ and PCOL groups simultaneously. In accordance with the ALP activity and gene expression data, calcific deposition in cells grown on $\mathrm{Fn}(10-50)$ and PCOL was observed as well. Conclusion: Despite the limitation of this study, the findings indicate that a surface coating of Fn enhances the proliferation, differentiation and mineralization of odontoblast-like cells by activation of integrin beta 1 (ITG B1). The promoting effects of Fn on MDPC-23 cells were achieved at a comparatively lower coating concentration than type I collagen $(300 \mu \mathrm{g} / \mathrm{mL})$. Specifically, it is suggested that the optimum coating concentration of Fn to be $10 \mu \mathrm{g} / \mathrm{mL}$.

Keywords: Fibronectin. Odontoblasts. Cell differentiation. Cell proliferation

${ }^{1}$ Health Sciences University of Hokkaido, School of Dentistry, Department of Oral Rehabilitation, Division of Clinical Cariology and Endodontology, Hokkaido, Japan. 


\section{Introduction}

Fibronectin (Fn) is a dimeric multi-domain glycoprotein (about $450 \mathrm{kDa}$ per dimer) that is found in circulation or tissue extracellular matrix (ECM). Two major types of $\mathrm{Fn}$ are present in vertebrates arising from alternative splicing of its pre-mRNA: soluble plasma Fn (corresponds to the aforementioned $\mathrm{CIg}$ ) and insoluble cellular Fn. Both of them contain various adhesive domains for cells and other proteins (collagen, fibrin, heparin), such as: the most widely known Arg-Gly-Asp (RGD) (aIIb $33, \operatorname{av} \beta 3, \operatorname{av} \beta 6, \operatorname{av} \beta 1$, a5 $\beta 1$, and a $8 \beta 1$ ligand $)^{9,21}$, the synergic site of RGD: PHSRN $^{4,18}$, Leu-Asp-Val (LDV) ( $a 4 \beta 1$ and a $4 \beta 7$ ligand) ${ }^{9}$, Arg-Glu-Asp-Val (REDV) ${ }^{10}$, IDAPS ( $a 4 \beta 1$ ligand) ${ }^{15}$, and KLDAPT ( $a 4 \beta 1$ and $a 4 \beta 7$ ligand) ${ }^{17}$. The plasma form of $\mathrm{Fn}$ (pFn) is predominantly synthesized by hepatocytes, circulates in blood and deposits rapidly upon tissue injury to initiate hemostasis, this deposition process is independent of other hemostasis factors, such as fibrinogen, von Willebrand factor, $\beta 3$ integrin, and platelet $^{30}$. Cellular $\mathrm{Fn}$ (CFn) is mainly produced by fibroblast, to a lesser extent by other cells, such as epithelial cell ${ }^{25}$, macrophage ${ }^{2}$, and endothelial cells ${ }^{20}$. cFn contributes to support the extracellular structure framework by actively binding with cells and other matrix proteins as mentioned above.

Previous histological localization study in tooth germ revealed that $\mathrm{Fn}$, which is present in the mesenchymal tissue, basement membrane, and predentine, was not detected in late pre-dentine and mineralized dentine. Further, epithelial tissues of tooth germ were negative for Fn except in the stellate reticulum ${ }^{12,28}$. Tooth development or odontogenesis is a complex process, which needs reciprocal interaction between epithelium and mesenchyme. Various growth factors, paracrine signal molecules ${ }^{27}$ and extracellular matrix (ECM) proteins ${ }^{6}$ are believed to be essential for this process. Among those, the importance of ECM proteins is becoming increasingly apparent, since serious changes were noted in oral cancer as compared with normal tissue because of the alteration of $\mathrm{ECM}^{26}$. As a ubiquitous ECM, it is reported that $\mathrm{Fn}$ is required for calvarial osteoblast differentiation and mineralization ${ }^{16}$. Since $\mathrm{Fn}$ is expressed in early pre-dentine and disappeared in mineralized mature dentine, it is thus reasonable to conceive that Fn might play some roles in the differentiation of dental mesenchyme into dentine-forming odontoblast.
Previously, Mizuno, et al. ${ }^{14}$ (2008) reported that Fn enhanced the osteocalcin (OCN) and osteopontin (OPN) gene expression in human dental pulp cells. However, the precise effect of $F n$ on cells of dental mesenchymal origin is still unclear to date. Hence, the current experiment seeks to uncover the potential interaction between $\mathrm{Fn}$ and odontoblast-like cells. To better imitate the real scenario that cells are surrounded by extracellular matrix proteins in situ, we examined the cell proliferation, differentiation and mineralization behavior in Fn-coated substrate using porcine type I collagen as a comparison ECM.

\section{Material and methods}

\section{Cell culture}

Rat odontoblast-like cell (MDPC-23 cell), a spontaneously immortalized cell line originally isolated from molar papillae, were cultured in Dulbecco Modified Eagle's Medium (DMEM) (Gibco, Gaithersburg, MD, USA) supplemented with $5 \%$ fetal bovine serum (FBS) $(10270-098, \mathrm{Gibco})$ at $37^{\circ} \mathrm{C}, 5 \%$ $\mathrm{CO}_{2}$ in a humidified atmosphere. The cells were rinsed with PBS, trypsinized (TrypLE ${ }^{\mathrm{TM}}$ Express $1 \times$, Phenol Red) (12605-010, Invitrogen, Carlsbad, CA, USA), and seeded at pre-determined concentrations. The medium was changed every other day. The cells used in this study were obtained from 25 to 33 passages.

\section{Protein coating on non-treated tissue culture plates}

Human plasma Fn was purchased from Gibco (33016-015), reconstituted in phosphate buffered saline (PBS) (Gibco) at a stock concentration of $1 \mathrm{mg} /$ $\mathrm{mL}$, aliquoted, then stored at $-30^{\circ} \mathrm{C}$ until use. Porcine skin type I collagen was obtained from Nitta gelatin ( $3 \mathrm{mg} / \mathrm{mL}$, Cell matrix type I-C, 140820). Non-tissue culture grade plates (96-well plate, 351177, Falcon; 24-well plate, 1820-024, Iwaki; 12-well plate, 351143, Falcon) coated with Fn were prepared by soaking the plates in a series of concentrations $(0.1,1,10,20,30$, $40,50 \mu \mathrm{g} / \mathrm{mL}$, herein referred to as Fn0.1, Fn1, Fn10, Fn20, Fn30, Fn40, Fn50, respectively), collagen was coated at the concentration of $300 \mu \mathrm{g} / \mathrm{mL}$ (PCOL300) as recommended by manufacturer. After overnight coating, the solution was aspirated and the wells were washed twice with PBS. The cells were rinsed with PBS, trypsinized, and seeded into the 96 -well plate $\left(5 \times 10^{3}\right.$ 
or $1 \times 10^{4} / \mathrm{mL} ; 100 \mu \mathrm{L}$ culture media/well), 24-well plate $\left(5 \times 10^{3}\right.$ or $1 \times 10^{4} / \mathrm{mL} ; 1 \mathrm{~mL}$ culture media/well) and the 12 -well plate $\left(1 \times 10^{4} / \mathrm{mL} ; 2 \mathrm{~mL}\right.$ culture media/ well). The cells were cultured in DMEM supplemented with 5\% FBS for the experiment. Inducer medium (10 mM $\beta$-glycerophosphate and $50 \mu \mathrm{g} / \mathrm{mL}$ ascorbic acid) (Wako, Osaka, Japan ${ }^{19}$ was added to the culture medium from day 5 . Cells seeded in wells coated with PBS served as the control.

\section{Cell morphology observation}

Light microscopy observation: cells were inoculated at the concentration of $1 \times 10^{4} / \mathrm{mL}$. Photos of the cells were taken under light microscopy (Olympus) after 20 hours culture in 12 well plate (non-treated, 351143, Falcon).

Immunofluorescence staining: MDPC-23 cells was seeded into 24 well plate (non-treated, 1820024, IWAKI) at the concentration of $5 \times 10^{3} / \mathrm{mL}$. Immunofluorescence staining was carried out on day 3. F-actin and nucleus were visualized by staining with Alexa Fluor $568^{\circledR}$ phalloidin (A12380) (Invitrogen) and DAPI (D9542) (Sigma, St Louis, MO, USA), respectively. Briefly, cells were fixed with $4 \%$ formaldehyde (16\%, methanol-free, 28906) (Thermo Fisher Scientific, Waltham, MA, USA) for 15 minutes, permeabilized with Triton-X-100 (0.1\%, v/v, in PBS) (T8787-100mL) (Sigma) for 5 minutes. Alexa Fluor $568^{\circledR}$ phalloidin was reconstituted in $1.5 \mathrm{~mL}$ methanol to generate the stock solution $(200 \mathrm{U} / \mathrm{mL})$. The stock solution was subsequently diluted $(0.01 \mathrm{U} / \mu \mathrm{L})$ and added into 24 well plate (200 $\mu \mathrm{L} /$ well). Tween $20(0.05 \%$, v/v) (Kanto Chemical) in PBS (PBST) was used to wash the cells after 1 hour incubation in room temperature. Finally, the cells were counterstained with DAPI (300 nM in PBS) for 5 minutes at room temperature and washed thoroughly by PBST. Immunofluorescence photographs were taken using EVOS ${ }^{\circledR}$ FLoid ${ }^{\circledR}$ Cell Imaging Station (Advanced Microscopy Group, Mill Creek, WA, USA).

\section{Cell proliferation assay}

Cells were seeded into a 96-well plate (non-treated, 351172 , Falcon) at the concentration of $5 \times 10^{3}$ or $1 \times 10^{4} / \mathrm{mL}$. After incubation for $1,2,4,6$ days, cell counting kit-8 (CCK-8) reagent (Dojindo, Kumamoto, Japan) was added to each well to a volume of $10 \%$ (10 $\mu \mathrm{L} /$ well), followed by incubation for another 1 hour and 45 minutes at $37^{\circ} \mathrm{C}, 5 \% \mathrm{CO}_{2}$ in a humidified atmosphere. The optical density was measured at 450 $\mathrm{nm}$ using a microplate reader (Bio-Rad, Hercules, CA, USA).

\section{Quantification of Alkaline Phosphatase (ALP) activity}

Cells $\left(1 \times 10^{4} / \mathrm{mL}\right)$ were seeded into Fibronectin and collagen-coated 12 well plates (non-treated) and incubated for five days in DMEM supplemented with $5 \%$ FBS. On day 5 , cells were removed from the culture plate using Triton-X-100 $(0.1 \%, w / w$, in distilled water) and sonicated (Bioruptor ${ }^{\circledR}$, Diagenode, Seraing, Belgium) for ten minutes on ice. The lysates were centrifuged for 15 minutes at $10,483 \times \mathrm{g}, 4^{\circ} \mathrm{C}$ (Hitachi Koki, Tokyo, Japan). The resulting supernatant was diluted and assayed for ALP activity (100-times dilution) (Wako, Osaka, Japan) and BCA protein quantification (2-times dilution) (Thermo Scientific, Rockford, IL, USA) according to the manufacturers' instructions. Absorbance was read at $405 \mathrm{~nm}$ and $570 \mathrm{~nm}$ for the ALP assay and the protein assay, respectively.

\section{Quantitative reverse transcription-polymerase chain reaction ( $\mathrm{qRT}$-PCR)}

Cells $\left(1 \times 10^{4} / \mathrm{mL}\right)$ were seeded into 12 well plates (non-treated). RNA was isolated from aliquots of cells harvested on day 7. The mRNA levels of bone sialoprotein (BSP), OCN, integrin beta 1 (ITGB1), ALP, OPN, and dentine matrix protein-1 (DMP-1) were measured using a quantitative RT-PCR machine (LightCycler ${ }^{\mathrm{TM}}$ Nano, Roche, Basel, Switzerland). The mRNAs were converted to cDNA using M-MLV reverse transcriptase (Invitrogen). Real time RT-PCR was carried out in a $20 \mu \mathrm{L}$ reaction system [cDNA: $1 \mu \mathrm{L}$; forward primer: $1 \mu \mathrm{L}$; backward primer: $1 \mu \mathrm{L}$; FastStart Essential DNA Green Master PCR grade $\mathrm{H}_{2} \mathrm{O}$ (Roche): $7 \mu \mathrm{L}$; FastStart Essential DNA Green Master $2 \times$ conc. (Roche): $10 \mu \mathrm{L}$ ]. The $2^{-\Delta \Delta \mathrm{ct}}$ method was used to calculate relative gene expression. The gene expression levels were normalized to $\beta$-actin mRNA level. Real time RT-PCR primer sequences and reaction conditions are listed in Figure 1 and 2, respectively. Primers were generated from Invitrogen.

\section{Alizarin red staining}

In the same manner, cells were cultured in 12-well plates to day 10 at the concentration of $5 \times 10^{3} / \mathrm{mL}$ (Low concentration) and $1 \times 10^{4} / \mathrm{mL}$ (High concentration). Cells were fixed using $10 \%$ neutral buffer formalin (Wako) for 20 minutes, then the cell monolayer was 


\begin{tabular}{|c|c|c|c|}
\hline $\begin{array}{c}\text { Gene name } \\
\begin{array}{c}\text { Rat DMP-1 } \\
\text { (NM_203493.3) }\end{array}\end{array}$ & Forward & Backward & Fragment size(bp) \\
\hline $\begin{array}{c}\text { Rat ALP } \\
\text { (NM_013059.1) }\end{array}$ & GGAAGGAGGCAGGATTGACCAC & GGGCCTGGTAGTTGTTGTGAGC & 338 \\
\hline $\begin{array}{c}\text { Rat BSP } \\
\text { (NM_012587.2) }\end{array}$ & CTGCTTTAATCTTGCTCTG & CCATCTCCATTTTCTTCC & 211 \\
\hline $\begin{array}{c}\text { Rat OCN } \\
\text { (NM_013414.1) }\end{array}$ & AGCTCAACCCCAATTGTGAC & AGCTGTGCCGTCCATACTTT & 190 \\
\hline $\begin{array}{c}\text { Rat OPN } \\
(\text { NM_012881.2) }\end{array}$ & TTTCCCTGTTTCTGATGAACAGTAT & CTCTGCTTATACTCCTTGGACTGCT & 228 \\
\hline $\begin{array}{c}\text { Rat ITGB1 } \\
\text { (NM_017022.2) }\end{array}$ & ACAAGAGTGCCGTGACAACT & AGCTTGATTCCAAGGGTCCG & 325 \\
\hline $\begin{array}{c}\text { Rat } \beta \text {-actin } \\
\text { (NM_031144.3) }\end{array}$ & AACCCTAAGGCCAACAGTGAAAAG & TCATGAGGTAGTCTGTGAGGT & 241 \\
\hline
\end{tabular}

Figure 1- Real time RT-PCR primer

\begin{tabular}{|c|c|c|c|c|c|}
\hline Gene name & Initialization & Denaturation & Annealing & Elongation & Cycle \\
\hline DMP-1 & $95^{\circ} \mathrm{C} 10 \mathrm{~min}$ & $95^{\circ} \mathrm{C} 15 \mathrm{~s}$ & $60^{\circ} \mathrm{C} 30 \mathrm{~s}$ & $72^{\circ} \mathrm{C} 30 \mathrm{~s}$ & 50 \\
\hline $\mathrm{ALP}$ & $95^{\circ} \mathrm{C} 10 \mathrm{~min}$ & $95^{\circ} \mathrm{C} 15 \mathrm{~s}$ & $55^{\circ} \mathrm{C} 30 \mathrm{~s}$ & $72^{\circ} \mathrm{C} 30 \mathrm{~s}$ & 45 \\
\hline $\mathrm{BSP}$ & $95^{\circ} \mathrm{C} 10 \mathrm{~min}$ & $95^{\circ} \mathrm{C} 15 \mathrm{~s}$ & $55^{\circ} \mathrm{C} 15 \mathrm{~s}$ & $72^{\circ} \mathrm{C} 30 \mathrm{~s}$ & 50 \\
\hline $\mathrm{OCN}$ & $95^{\circ} \mathrm{C} 10 \mathrm{~min}$ & $95^{\circ} \mathrm{C} 15 \mathrm{~s}$ & $55^{\circ} \mathrm{C} 30 \mathrm{~s}$ & $72^{\circ} \mathrm{C} 30 \mathrm{~s}$ & 50 \\
\hline OPN & $95^{\circ} \mathrm{C} 10 \mathrm{~min}$ & $95^{\circ} \mathrm{C} 15 \mathrm{~s}$ & $55^{\circ} \mathrm{C} 30 \mathrm{~s}$ & $72^{\circ} \mathrm{C} 30 \mathrm{~s}$ & 45 \\
\hline ITGB1 & $95^{\circ} \mathrm{C} 10 \mathrm{~min}$ & $95^{\circ} \mathrm{C} 15 \mathrm{~s}$ & $59.9^{\circ} \mathrm{C} 30 \mathrm{~s}$ & $72^{\circ} \mathrm{C} 40 \mathrm{~s}$ & 45 \\
\hline$\beta$-actin & $95^{\circ} \mathrm{C} 10 \mathrm{~min}$ & $95^{\circ} \mathrm{C} 15 \mathrm{~s}$ & $53^{\circ} \mathrm{C} 30 \mathrm{~s}$ & $72^{\circ} \mathrm{C} 40 \mathrm{~s}$ & 50 \\
\hline
\end{tabular}

Figure 2- Real time RT-PCR reaction condition

stained with Alizarin red $\mathrm{S}$ solution $(1 \%, \mathrm{w} / \mathrm{v}$, in water, $\mathrm{pH} 4.0$; Wako). Photographs were taken using a digital imaging system (Funakoshi, Tokyo, Japan) incorporating an inverted digital camera (Canon, Tokyo, Japan).

\section{Data analysis}

Cell proliferation, ALP activity, and real time RTPCR data were independently subjected to one-way analysis of variance. Once the null hypothesis of absence of differences among groups was rejected, Tukey's multiple comparison tests were applied for pairwise comparison. A significance level of $5 \%$ was set for all analysis.

\section{Results}

Fn promoted MDPC-23 cells spreading and proliferation

Photographs of light microscopy cells indicated that cells adopted well spread shape in Fn (10-50) and PCOL300 after 20 hours (Figure 3), but those cultured on control, Fn (0.1-1) were poorly spread, moreover, the attached number of cells in the three groups were much lower than Fn (10-50) and PCOL300. Given that cells growth and spreading remain comparatively unchanged in Fn with concentration over $10 \mu \mathrm{g} / \mathrm{mL}$, only the immunostaining of cells grown on Fn10 was shown in Figure 4. In Figure 4, regular and parallel actin filaments are clearly observed in cells cultured on Fn (10-50) and PCOL300; however, cells assumed a polygonal or round shape while growing on Fn1. To quantify the cell proliferation activity, MDPC-23 cells were cultured in 96 well plate coated with Fn or PCOL. To further evaluate the biocompatibility of Fn, cells were inoculated at two concentrations (Low concentration: $5 \times 10^{3} / \mathrm{mL}$ and high concentration: $1 \times 10^{4} / \mathrm{mL}$ ). Cells fail to grow in low concentration group in control well (Figure 5a); however, those cultured in Fn exhibited concentration-dependent fashion (0.1-10) of growth for the points tested four times, when the coating concentration of Fn was over $10 \mu \mathrm{g} / \mathrm{mL}$, proliferation activity was maintained at a constant level; moreover, the proliferation activity in PCOL300 was quite similar to that in Fn (10-50), although significant differences exist between some Fn groups and PCOL300. In the higher concentration 


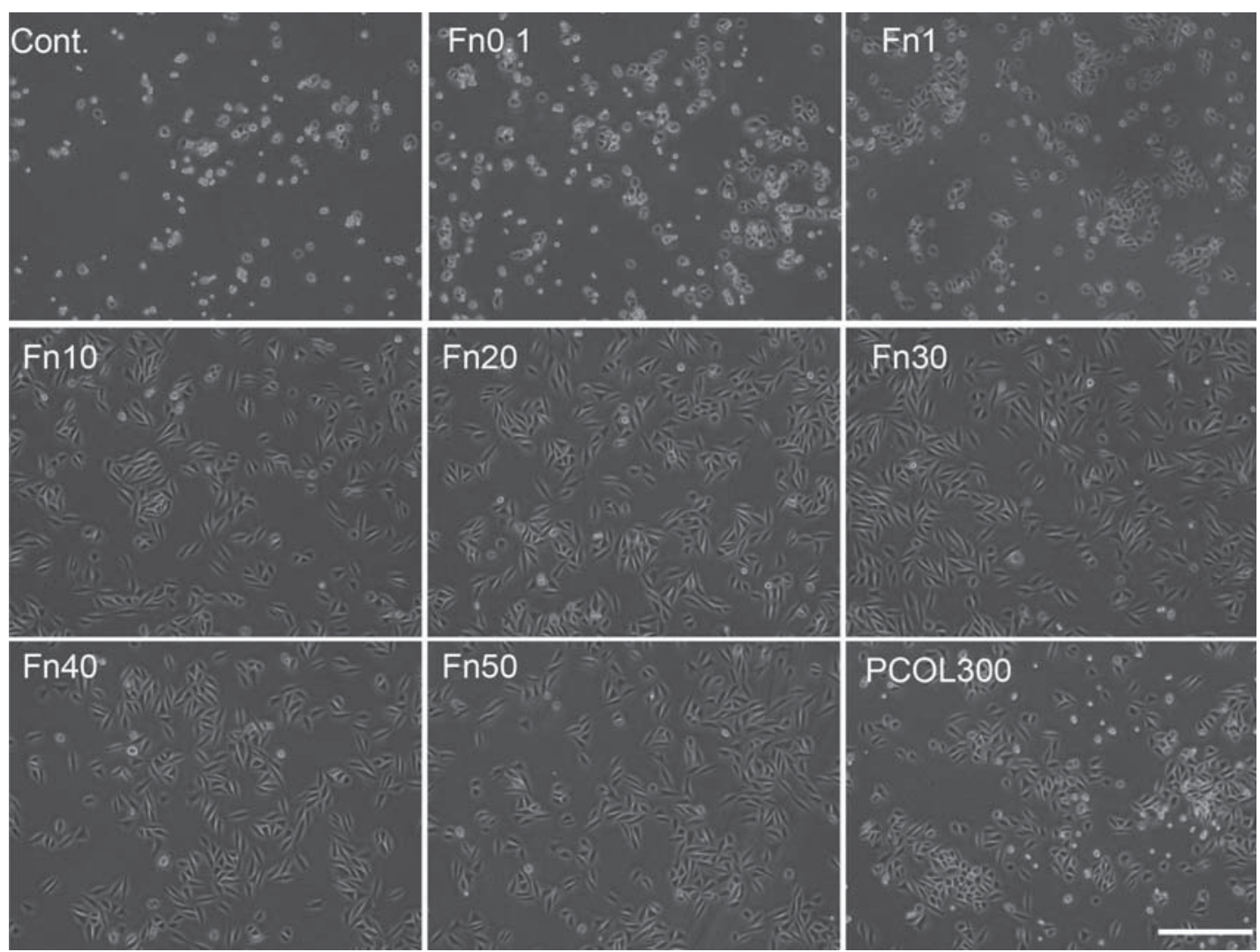

Figure 3- Cell morphology observation by light microscopy

MDPC-23 cells were seeded to 12 well plate (non-treated tissue culture polystyrene) at the concentration of $1 \times 10^{4} / \mathrm{mL}$ in $\mathrm{DMEM}$ supplemented with $5 \%$ FBS. The photograph was taken 20 hours after inoculation. Cells adopted well spread and spindle shape in Fn(1050 ) and PCOL-300, while those in control and Fn(0.1-1) were in round shapes. (Scale bar: $400 \mu \mathrm{m}$ )

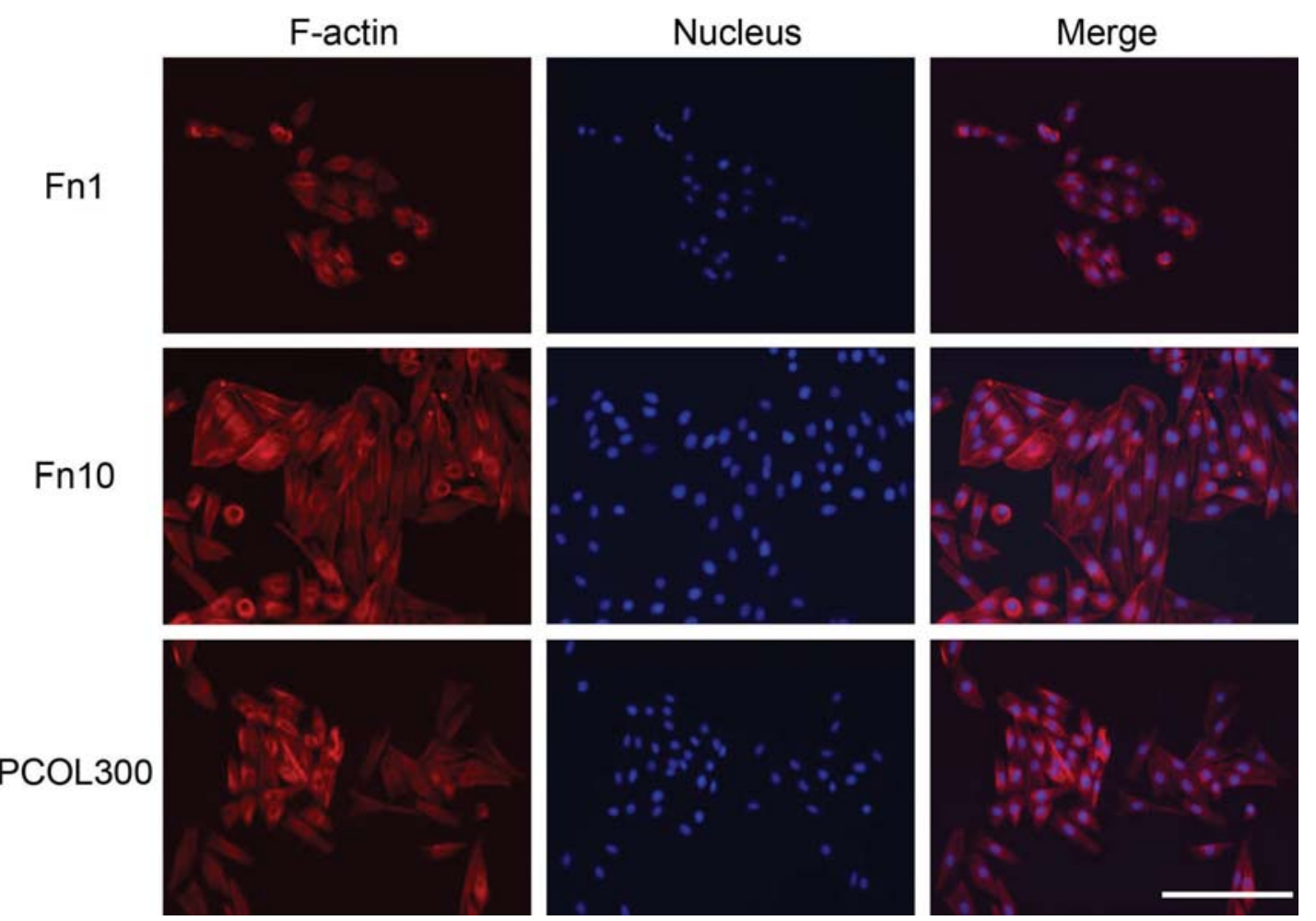

Figure 4- Immunofluorescence staining

MDPC-23 cells in Fn(10) and PCOL-300 were well spread, F-actin formation was extensively activated in these two groups, while most of the cells grown in $\mathrm{Fn}(1)$ remain round in shape. (Scale bar: $200 \mu \mathrm{m}$ ) 
group (Figure 5b); cells did increase in control well, whereas the growth speed was rather low when compared with the Fn and PCOL.
Fn increased ALP activity and the expression of odontogenic differentiation markers

Alkaline phosphatase was established to be one of the phenotypic markers of odontoblastic differentiation
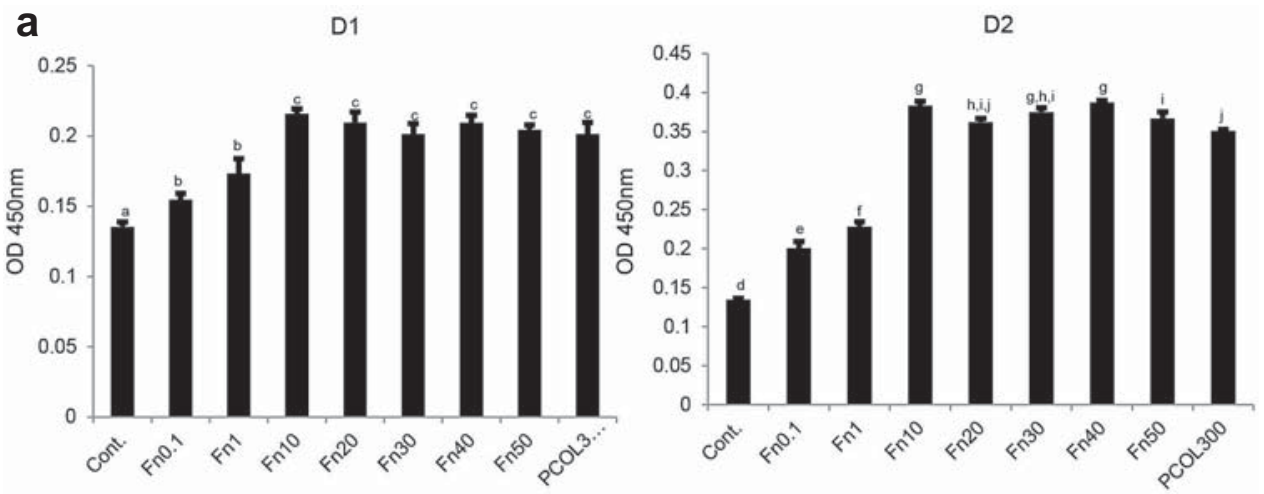

D6
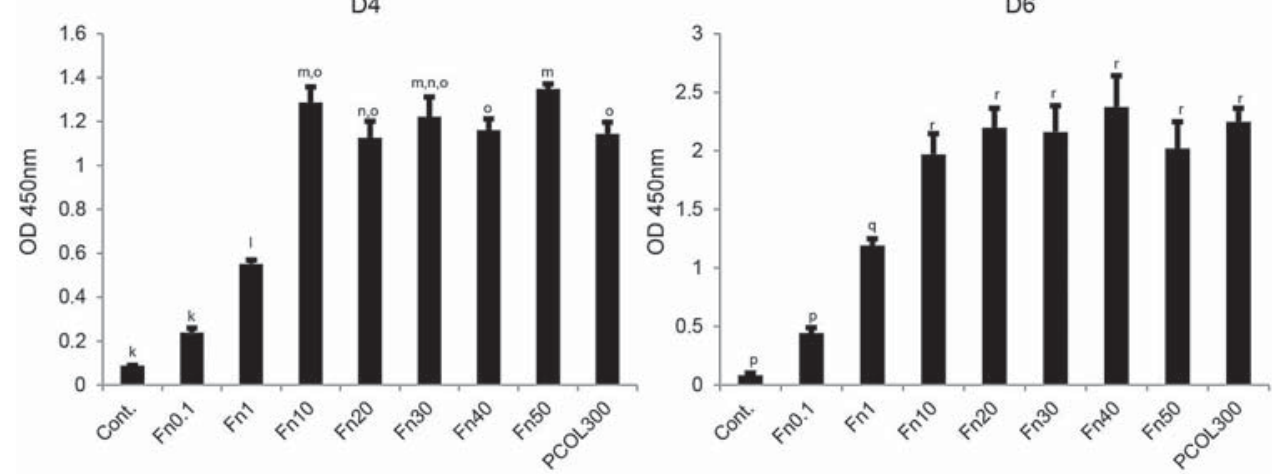

b
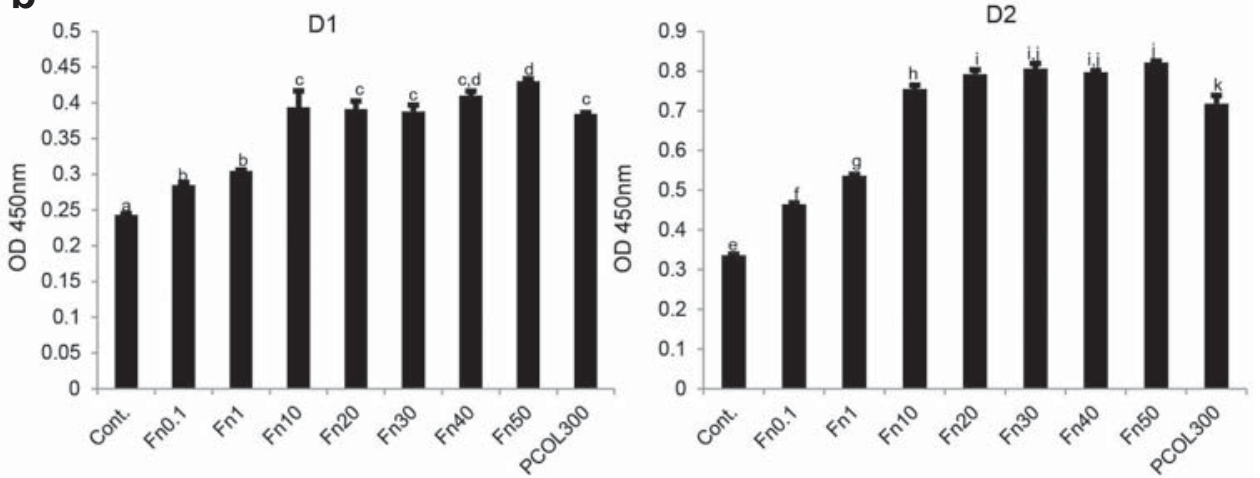

D4

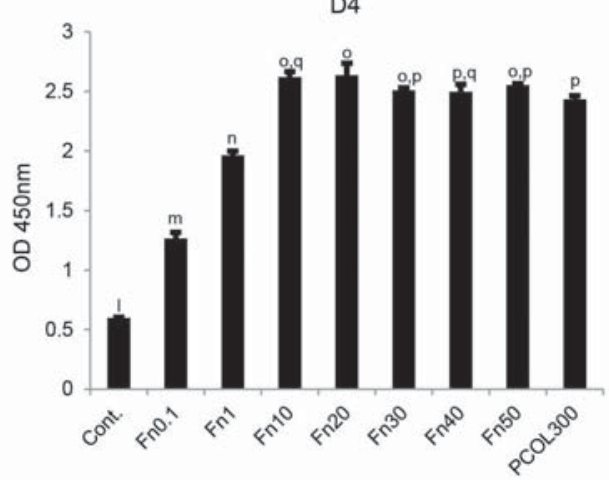

Figure 5- Cell proliferation activity

MDPC-23 cells were seeded to 96 well plate (non-treated tissue culture polystyrene) at the concentration of $5 \times 10^{3} / \mathrm{mL}$ (Figure $5 \mathrm{a}$ ) or $1 \times 10^{4} / \mathrm{mL}$ (Figure $5 \mathrm{~b}$ ) in DMEM supplemented with $5 \%$ FBS. Absorbance was read at wavelength of $450 \mathrm{~nm}$. All data represents average \pm standard deviation (SD) from three separate experiments. Different symbols in each panel mean significant differences $(p<0.05$, Tukey's test). OD: optical density. D1, D2, D4, D6 mean day 1, day 2, day 4, and day 6, respectively 
D5

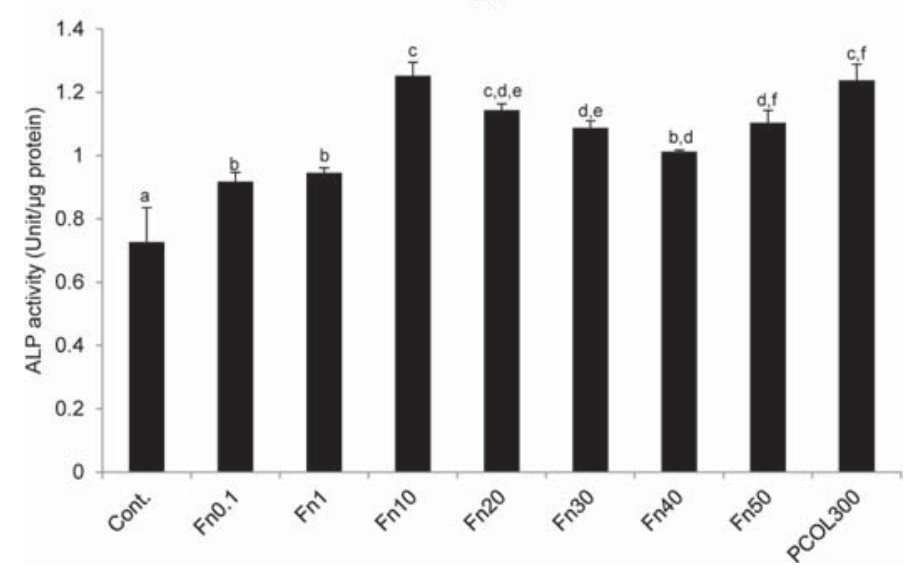

Figure 6- ALP activity

Cells were seeded to 12 well plate (non-treated tissue culture polystyrene) at the concentration of $1 \times 10^{4} / \mathrm{mL}$ in $\mathrm{DMEM}$ supplemented with $5 \%$ FBS. ALP activity in all the experimental groups was enhanced, in particular, Fn(10) exhibited the highest ALP activity as compared with the other groups. All data represents average \pm standard deviation (SD) from three separate experiments. Different symbols mean significant differences ( $p<0.05$, Tukey test). D5 means day 5

and a critical enzyme in calcification. ALP activity was found to be the highest in Fn10 group (1.25 \pm 0.04 $\mathrm{U} / \mu \mathrm{g}$ protein) at day 5 (Figure 6 ), while that of PCOL300 (1.24 $\pm 0.05 \mathrm{U} / \mu \mathrm{g}$ protein) was almost the same as Fn10. ALP activity in Fn0.1 (0.92 $0.03 \mathrm{U} /$ $\mu \mathrm{g}$ protein) and $\mathrm{Fn} 1(0.95 \pm 0.02 \mathrm{U} / \mu \mathrm{g}$ protein) were significantly lower than that of Fn10, Fn20 (1.14 0.02 $\mathrm{U} / \mu \mathrm{g}$ protein), Fn30 (1.09 $\pm 0.02 \mathrm{U} / \mu \mathrm{g}$ protein), Fn50 $(1.10 \pm 0.04 \mathrm{U} / \mu \mathrm{g}$ protein), and PCOL300.

Similar enhancive effects were also confirmed for the mRNA expression of phenotypic markers (Figure 7). Among the markers tested, we observed that especially BSP (three fold) and OCN (2.5-fold) were significantly promoted in Fn (10-50), the fold change was also higher than PCOL300 (2.2-fold in BSP; 1.6fold in OCN). ITGB1, ALP, and DMP1 were slightly up-regulated in Fn (10-50) and PCOL300. OPN was significantly promoted in all the coating concentration of Fn but not PCOL300.

\section{Fn facilitated MDPC-23 cells calcification}

To enhance calcification, $\beta$-GP and ascorbic acid was incorporated into culture media from 5 days. Similarly, two concentrations equal to the proliferation experiment were used for cell inoculation. After 10 days, calcifying nodules appeared in Fn (10-50) and PCOL300 in both low (Figure 8 upper) and high concentration groups (Figure 8 lower); however, higher inoculation number leads to more calcifying nodules.

\section{Discussion}

Fn is an adhesive extracellular matrix glycoprotein that is involved in a variety of physiological and pathological processes. Small interfering RNA against Fn abrogated cleft formation and branching morphogenesis, while exogenous Fn facilitated and accelerated the branching and cleft formation. More importantly, Fn was found to mediate the conversion process of cell-cell adhesion to cell-matrix adhesion in human salivary epithelial cells ${ }^{24}$. Although $\mathrm{Fn}$ has been extensively studied in the development of tissues and organs, its role in the regulation of odontoblast activity remains elusive. To determine the precise role of $\mathrm{Fn}$ in the regulation of odontoblast activity, we evaluated proliferation and differentiation of MDPC-23 cells in Fn-coated substrates using type I collagen as a comparison with matrix protein. This study showed that culturing MDPC-23 cells in the presence of Fn can direct MDPC-23 cells down lineage of mineralizing tissue-forming cells. Specifically, key markers of odontogenic differentiation (intracellular ALP activity, phenotypic gene expression) were greater with MDPC-23 cells cultured in Fn. Furthermore, Fn facilitated calcific deposition of cells at a low seeding concentration when exposed to mineralization factors. The data presented here confirm that a regulatory relationship exists between $\mathrm{Fn}$ and odontoblast-like cell. The study highlighted natural cues for odontoblast differentiation within the local microenvironment in vitro.

Cells started to spread merely one hour after inoculation in Fn (10-50) (coated in either non-treated 
BSP D7

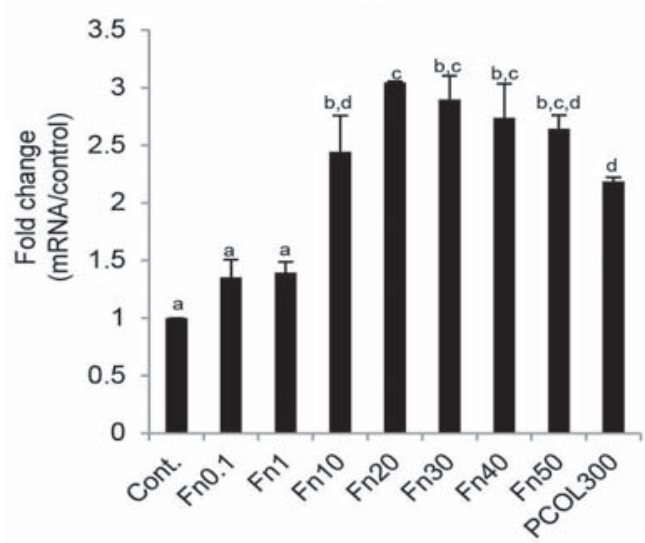

ITGB1 D7
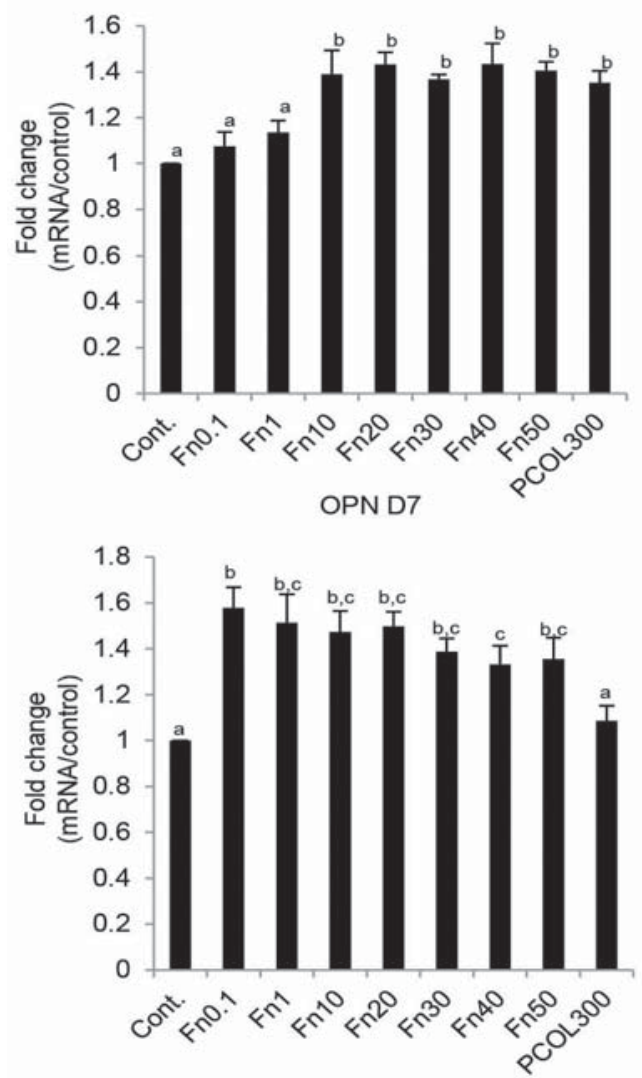

OCN D7

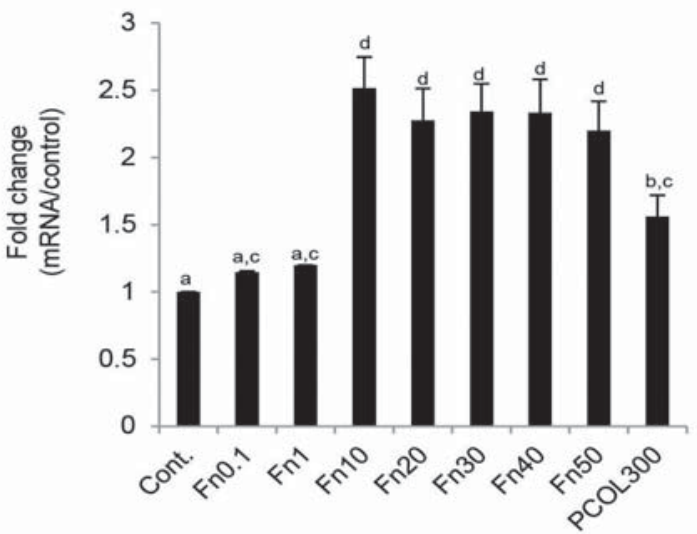

ALP D7
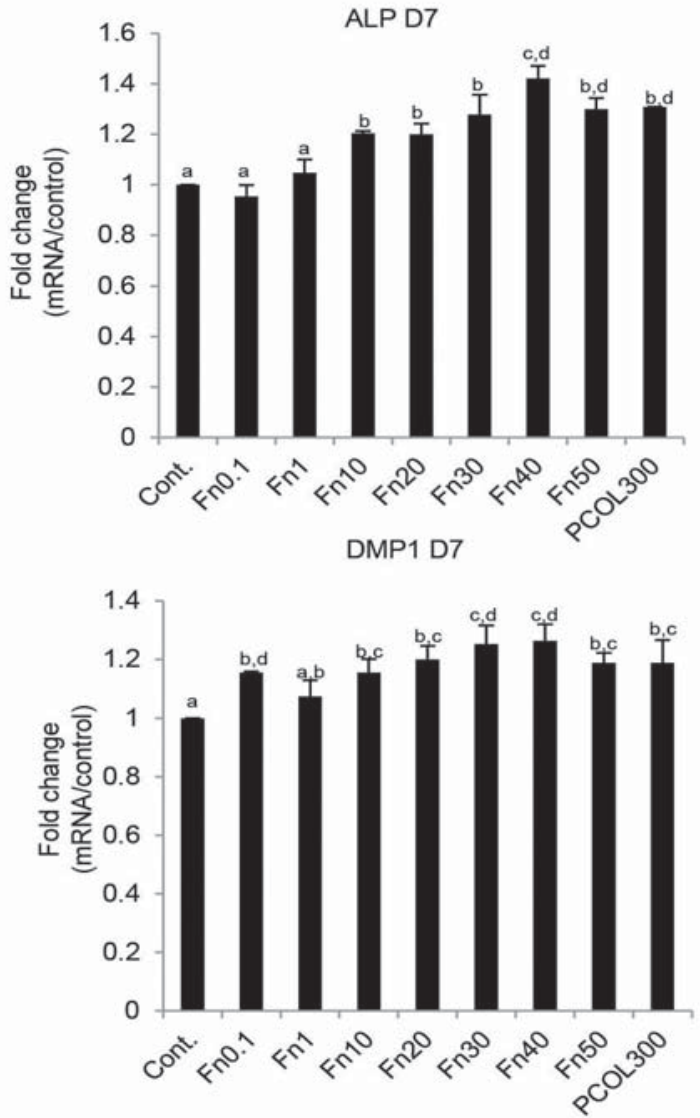

Figure 7- Real time RT-PCR

MDPC-23 cells were seeded to 12 well plate (non-treated tissue culture polystyrene) at the concentration of $1 \times 10^{4} / \mathrm{mL}$ in DMEM supplemented with $5 \%$ FBS. Odontogenesis related markers were significantly up-regulated in Fn and PCOL-300-treated substrates, especially, the expression of BSP and OCN was found to be markedly augmented in $\mathrm{Fn}(10-50)$. All data represent average \pm standard deviation (SD). Different symbols in each group mean significant differences ( $p<0.05$, Tukey test). $D 7$ means day 7

polystyrene or tissue culture polystyrene), which is much earlier than those grown on control (2 days) and type I collagen (18 hours) (data not shown). Actin is a family of globular proteins that form microfilaments. It is comprised of free monomer G-actin (globular) and linear polymer F-actin (filamentous). Actin is a mechanosensing tool ${ }^{7}$ and transduces the extracellular signals to change the shape of the cell, direct cell migration and differentiation. F-actin staining clearly showed that microfilaments formation were successfully initiated and activated on Fn10 and PCOL300, indicating that mechanosensing and signaling transduction was promoted in cells. Next, quantification of proliferation activity was conducted using CCK-8 assay. We found that Fn (0.1-50) and PCOL300 significantly increase cell proliferation as compared with the control. The activity exhibited concentration-dependent trend when concentration of Fn was lower than $10 \mu \mathrm{g} / \mathrm{mL}$. It reached a state of plateau when the coating concentration of Fn was over 


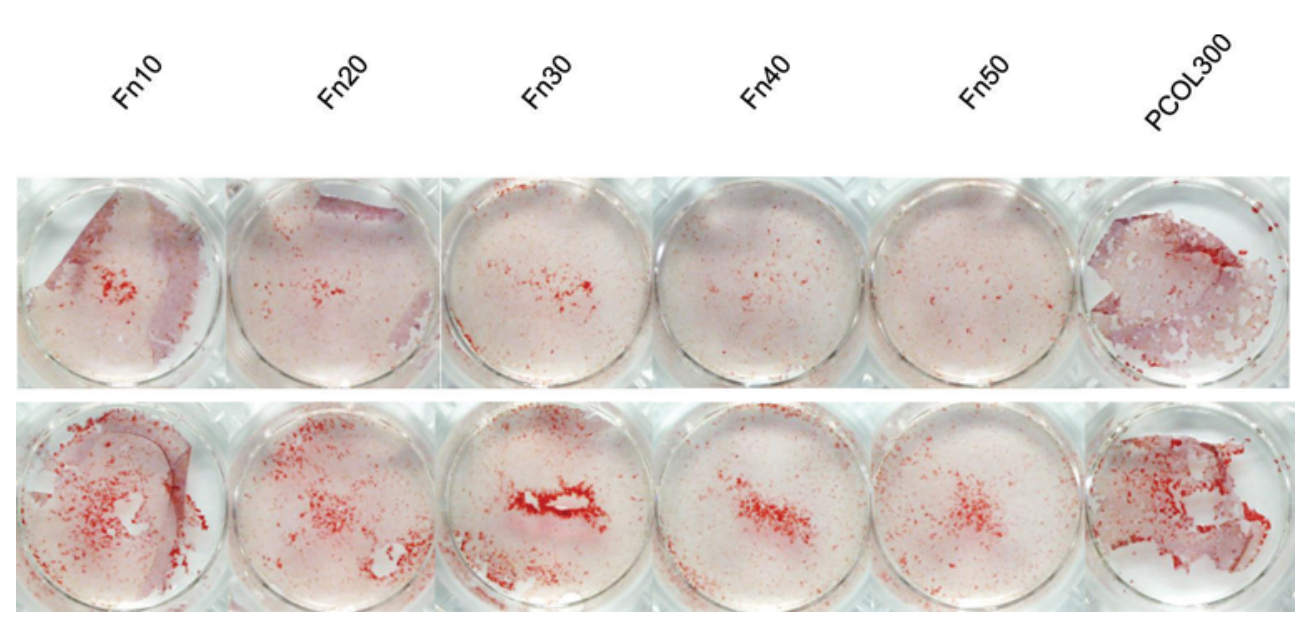

Figure 8- Alizarin red staining

Cells were inoculated in 24 well plate (non-treated tissue culture polystyrene) at the concentration of $5 \times 10^{3} / \mathrm{mL}$ (upper) or $1 \times 10^{4} / \mathrm{mL}$ (lower). Odontogenic reagents were added in the same manner as Figure 6, and staining was conducted at 10 days of culture. Calcification nodules were clearly observed in $\mathrm{Fn}(10-50)$ and PCOL300 in both low and high cell seeding density

$10 \mu \mathrm{g} / \mathrm{mL}$. Further, we showed that the non-treated polystyrene was not able to support the growth of MDPC-23 cells when the cell concentration was only $5 \times 10^{3} / \mathrm{mL}$. When inoculation number increased to $1 \times 10^{4} / \mathrm{mL}$, the control did maintain a certain level of cell growth, the cell viability was markedly lower than that in Fn and PCOL300 though. The proliferation data revealed that $\mathrm{Fn}$ is highly biocompatible, coating of Fn to hydrophobic polystyrene facilitated cell adhesion and growth. Indeed, although Fn was not expressed in mineralized dentin and epithelial tissue in the mouse tooth germ, a strong staining of Fn using its antibody was detected between dental epithelium and mesenchyme, Thesleff, et al. ${ }^{28}$ (1979) hence inferred that Fn may be a potential anchorage site for cells of mesenchymal origin to differentiate into mature odontoblasts. The fluorescence staining data together with the proliferation data of this study provide a direct evidence of $\mathrm{Fn}$ as a potent odontoblast-like cell-adhesive, which allows MDPC-23 cells to attach, spread and proliferate rapidly.

Both calcium deposition and elevation of ALP activity were observed by $\mathrm{Fn}$ exposure. The results indicate that $F n$ promoted mineralization and is associated with increased ALP activity, since ALP can degrade $\beta$-GP and release phosphorus ${ }^{1}$, an early enhancement of ALP activity denotes accelerating differentiation process toward mineralizing tissueforming cells. Besides the enhanced ALP activity, the markedly increased expression of mineralized tissue-forming genes was detected as well. BSP, OPN and DMP1 are Small Integrin Binding Ligand $\mathrm{N}$-linked Glycoprotein (SIBLING) members. They possess distinct temporal and spatial expression profiles and functions. BSP is a component of mineralized tissues and is suggested to constitute approximately $8 \%$ of all non-collagenous proteins found in bone and cementum. BSP has a specific role in mediating the initial stages of connective tissue mineralization ${ }^{5}$ and is strongly expressed in the odontoblast-like cells of reparative dentine ${ }^{11}$. OPN, a highly phosphorylated glycoprotein, is important for type I collagen secretion in reparative dentine formation by newly differentiated odontoblast-like cells ${ }^{23}$. DMP1 is an RGD containing acidic phosphoprotein that was identified from rat incisor cDNA library; it is an inductive factor for dental pulp stem cells to differentiate into odontoblast ${ }^{3}$. OCN, a non-collagenous protein found in both dentin and bone, is found to be strongly expressed at 2 and 3 days post-tooth preparation, its expression correlates with reactionary dentine formation ${ }^{8}$. The strongest expression of OCN in Fn provides evidence of an earlier differentiation of MDPC-23 cells on the substrates. ITGB1, also known as CD29, is able to associate with a number of alpha integrin to form various types of heterogeneous integrin dimers, a recent paper suggested that interaction between fibronectin and ITGB1 is essential for ameloblast differentiation and enamel formation ${ }^{22}$. In particular, among the genes tested, BSP and OCN were found to be enhanced by a much higher fold change on $\mathrm{Fn}(10-50)$ than PCOL300, which indicated that Fn possesses a stronger capacity of initiating odontogenic differentiation as compared with PCOL300. Indeed, a previous study using dog dental pulp also confirmed that pulp cells can be stimulated to exhibit odontoblastic phenotype in response to a surface coating of plasma fibronectin even in the absence of exogenous inductive molecules ${ }^{29}$. The 
up-regulation of those mineralizing tissue markers suggested that $\mathrm{Fn}$ is a suitable cell expansion matrix to retain high odontogenic differentiation potential and provide a synergistic effect in the presence of odontogenic factors ( $\beta$-GP and ascorbic acid) in vitro. Furthermore, concomitant increased expression of ITGB1 suggests that the up-regulation of odontogenic markers might be mediated, at least partially, by activation of ITGB1.

Cells secrete a wide variety of extracellular matrix that is crucial for the maintenance of normal function. ECM plays the role not only as a mechanical and structural framework, it also modulates many aspects of cell behavior, such as adhesion, migration, differentiation, and mineralization. To gain further insight into the in vitro effects of fibronectin and type I collagen, we have performed staining of calcified nodule. Alizarin red $\mathrm{s}$ was used as a vital stain for mineralization.

Fn and PCOL were pre-coated in a sterile environment in 24 well plate (non-treated polystyrene) in two different cell concentrations. Calcification of cells was induced by $\beta$-GP from 5 days. After 10 days, calcifying nodules appeared in Fn (10-50) and PCOL300-treated groups in both cell concentration groups, however, the number of nodules in groups with high number of cells was observed to be comparatively higher than that of low cell number groups. This phenomenon correlates well with previous studies using umbilical cord stem cells ${ }^{31}$ and human bone marrow stromal cells ${ }^{13}$, indicating that not only the ECM but also initial seeding density is a critical factor in determining the late stage mineralization intensity of cells. In addition, cells started to detach from control and Fn (0.1-1) at around 8 days in culture, which is the reason we do not show the alizarin staining of control and Fn (0.1-1). This has prompted us to think that cell attachment strength in Fn (10-50) is higher than that on control and Fn (0.1-1). Further detachment strength test between cells and Fn or collagen needs to be carried out.

\section{Conclusion}

The proliferation of MDPC-23 cells cultured on polystyrene preadsorbed with Fn was promoted. Further, an early differentiation marker of odontoblast, ALP activity was significantly augmented in cells grown on Fn-treated polystyrene. The expression of odontogenesis' markers during the differentiation and mineralization phase was increased by coated Fn. Finally, the mineralization of cells was facilitated by Fn as well. The results suggest that, a surface coating of polystyrene with $\mathrm{Fn}$ at the concentration of $10 \mu \mathrm{g} /$ $\mathrm{mL}$ or more effectively supported the proliferation, differentiation and mineralization of odontoblastlike cells; moreover, this inductive effects of Fn was achieved at a coating concentration markedly lower than type I collagen $(300 \mu \mathrm{g} / \mathrm{mL})$.

\section{Acknowledgements}

The study was supported by a grant-in-aid for scientific research from the Japanese Society for the Promotion of Science (Grant No.15K15702 and No.15H05024) and a research grant (May 2016-March 2017) for young Chinese researchers in Japan from The Japan China Medical Association (JCMA). The authors deny any conflict of interest related to this study.

\section{References}

1- Ahlers J. The mechanism of hydrolysis of beta-glycerophosphate by kidney alkaline phosphatase. Biochem J. 1979;149(3):535-46

2- Alitalo K, Hovi T, Vaheri A. Fibronectin is produced by human macrophages. J Exp Med. 1980;151(3):602-13.

3- Almushayt A, Narayanan K, Zaki AE, George A. Dentin matrix protein 1 induces cytodifferentiation of dental pulp stem cells into odontoblasts. Gene Ther. 2006;13(7):611-20.

4- Aota S, Nomizu M, Yamada KM. The short amino acid sequence ProHis-Ser-Arg-Asn in human fibronectin enhances cell-adhesive function. J Biol Chem. 1994;269(40):24756-61.

5- Chen J, Shapiro HS, Sodek J. Development expression of bone sialoprotein mRNA in rat mineralized connective tissues. J Bone Miner Res. $1992 ; 7(8): 987-97$.

6- Fukumoto S, Yamada Y. Review: extracellular matrix regulates tooth morphogenesis. Connect Tissue Res. 2005;46(4-5):220-6.

7- Hayakawa K, Tatsumi H, Sokabe M. Mechano-sensing by actin filaments and focal adhesion proteins. Commun Integr Biol. 2012;5(6):572-7

8- Hirata M, Yamaza T, Mei YF, Akamine A. Expression of osteocalcin and Jun $D$ in the early period during reactionary dentin formation after tooth preparation in rat molars. Cell Tissue Res. 2005;319(3):455-65. 9- Humphries JD, Byron A, Humphries MJ. Integrin ligands at a glance. J Cell Sci. 2006;119(Pt 19):3901-3.

10- Humphries MJ, Akiyama SK, Komoriya A, Olden K, Yamada KM. Identification of an alternatively spliced site in human plasma fibronectin that mediates cell type-specific adhesion. J Cell Biol. 1986;103(6 Pt 2):2637-47

11- Hwang YC, Hwang IN, Oh WM, Park JC, Lee DS, Son HH. Influence of TGF-beta1 on the expression of BSP, DSP, TGF-beta1 receptor I and Smad proteins during reparative dentinogenesis. J Mol Histol. 2008;39(2):153-60

12- Kubler MD, Lesot H, Ruch JV. Temporo-spatial distribution of matrix and microfilament components during odontoblast and ameloblast differentiation. Roux's Arch Dev Biol. 1988;197(4):212-20. 
13- Lode A, Bernhardt A, Gelinsky M. Cultivation of human bone marrow stromal cells on three-dimensional scaffolds of mineralized collagen: influence of seeding density on colonization, proliferation and osteogenic differentiation. J Tissue Eng Regen Med. 2008;2(7):400-7. 14- Mizuno M, Banzai Y. Calcium ion release from calcium hydroxide stimulated fibronectin gene expression in dental pulp cells and the differentiation of dental pulp cells to mineralized tissue forming cells by fibronectin. Int Endod J. 2008;41(11):933-8.

15- Mould AP, Humphries MJ. Identification of a novel recognition sequence for the integrin alpha 4 beta 1 in the $\mathrm{COOH}$-terminal heparinbinding domain of fibronectin. EMBO J. 1991;10(13):4089-95.

16- Moursi AM, Globus RK, Damsky $\mathrm{CH}$. Interactions between integrin receptors and fibronectin are required for calvarial osteoblast differentiation in vitro. J Cell Sci. 1997;110(Pt 18):2187-96.

17- Moyano JV, Carnemolla B, Domínguez-Jiménez C, García-Gila M, Albar JP, Sánchez-Aparicio $P$, et al. Fibronectin type III5 repeat contains a novel cell adhesion sequence, KLDAPT, which binds activated alpha4beta 1 and alpha4beta 7 integrins. J Biol Chem. 1997;272(40):24832-6.

18- Ochsenhirt SE, Kokkoli E, McCarthy JB, Tirrell M. Effect of RGD secondary structure and the synergy site PHSRN on cell adhesion, spreading and specific integrin engagement. Biomaterials. 2006;27(20):3863-74.

19- Park JB. The effects of dexamethasone, ascorbic acid, and $\beta$-glycerophosphate on osteoblastic differentiation by regulating estrogen receptor and osteopontin expression. J Surg Res. 2012;173(1):99-104.

20- Peters JH, Sporn LA, Ginsberg MH, Wagner DD. Human endothelial cells synthesize, process, and secrete fibronectin molecules bearing an alternatively spliced type III homology (ED1). Blood. 1990;75(9):18018.

21- Pierschbacher MD, Ruoslahti E. Cell attachment activity of fibronectin can be duplicated by small synthetic fragments of the molecule. Nature. 1984;309(5963):30-3.
22- Saito K, Fukumoto E, Yamada A, Yuasa K, Yoshizaki K, Iwamoto $\mathrm{T}$, et al. Interaction between fibronectin and beta1 integrin is essential for tooth development. PLoS One. 2015;10(4):e0121667.

23- Saito K, Nakatomi M, Ida-Yonemochi H, Ohshima H. Osteopontin is essential for type I collagen secretion in reparative dentin. J Dent Res. 2016;95(9):1034-41.

24- Sakai T, Larsen M, Yamada KM. Fibronectin requirement in branching morphogenesis. Nature. 2003;423(6942):876-81.

25- Seebacher T, Marianne M, Kornblihtt AR, Bade EG. Fibronectin is induced by epidermal growth factor, but not by dexamethasone or cyclic AMP in rat liver epithelial cells. FEBS Lett. 1988;239(1):113-6. 26- Sharma M, Sah P, Sharma SS, Radhakrishnan R. Molecular changes in invasive front of oral cancer. J Oral Maxillofac Pathol. 2013;17(2):240-7.

27- Thesleff I, Mikkola M. The role of growth factors in tooth development. Int Rev Cytol. 2002;217:93-135.

28- Thesleff I, Stenman S, Vaheri A, Timpl R. Changes in the matrix proteins, fibronectin and collagen, during differentiation of mouse tooth germ. Dev Biol. 1979;70(1):116-26.

29- Tziafas D, Alvanou A, Kaidoglou K. Dentinogenic activity of allogenic plasma fibronectin on dog dental pulp. J Dent Res. 1992;71(5):118995.

30- Wang YM, Reheman A, Spring CM, Kalantari J, Marshall AH, Wolberg AS, et al. Plasma fibronectin supports hemostasis and regulates thrombosis. J Clin Invest. 2014;124(10):4281-93.

31- Zhou H, Weir MD, Xu HH. Effect of cell seeding density on proliferation and osteodifferentiation of umbilical cord stem cells on calcium phosphate cement-fiber scaffold. Tissue Eng Part A. 2011;17(21-22):2603-13. 